\title{
Homelessness in Queensland mining communities: A down payment on Australia's wealth or inevitable product of a neo-liberalist society's response to the cyclical fortunes of mining
}

\section{Shane Warren}

School of Human Services and Social Work

Griffith University

\section{Donna McDonald}

School of Human Services and Social Work

Griffith University

\section{Donna McAuliffe}

School of Human Services and Social Work

\section{Griffith University}

\section{Abstract}

The mining boom in Australia of the first decade of the Twenty-First Century yielded prosperity for many Australians living in rural, regional and urban locations. This sense of prosperity was grounded in the widely reported experiences of people usually employed directly through the mining industry, or related industry, on high incomes, able to afford regular overseas holidays, ownership of multiple properties, material possessions and other hallmarks of an affluent lifestyle. However, less 
attention was given to vulnerable and homeless Australians in mining communities who did not benefit at all during the mining boom. In fact what evidence does exist indicates their disadvantage was further compounded through the high cost of housing. It is now widely accepted that the mining industry has been in a state of downturn over the last three years and this has served to highlight the social issues facing mining communities now and into the future. What is to be learnt from the decade long mining boom? Specifically this paper critiques the evidence, research literature and theories about urban-centric homelessness and assesses their relevance to homelessness in mining communities. This paper argues that the dynamics of homelessness in mining communities challenge existing homelessness theory and knowledge and argues that further evidence is needed to properly understand structural causes of homelessness in mining communities and to guide policy responses that may help prevent homelessness or otherwise assist homeless people access housing and support services. Identifying the mining boom and mining downturn cycle will be explored. Finally this paper outlines the case for further research to improve policy and planning responses to address homelessness in these communities taking into account planning requirements to address the mining boom and down turn cycle.

Keywords: Homelessness, mining boom, mining downturn, mining communities

\section{Introduction}

Despite the best efforts of numerous scholars over the last 30 years, homelessness research has tended to focus mainly on the experiences of homeless people in large metropolitan cities. In particular narratives of inner city rough sleepers continue to dominate human interest stories in mainstream media. The academic and media focus on homeless people as almost exclusively rough sleepers in urban areas has reinforced the stereotype of homeless people as the older man or woman with alcohol problems sleeping in a public park or homeless young person involved in substance abuse, crime and prostitution in CBDs of capital cities. While these stereotypes continue to be grounded in the reality of many homeless people and highlight the extreme vulnerability of homeless people they also serve to limit a fuller 
understanding of the contexts in which people experience homelessness. Homelessness has been constructed and defined in a number of ways and has also been considered in the context of specific demographic groups including young people, families, single adults and women and children who are homeless as a result of escaping domestic and family violence. The purpose of this paper is to critique existing theory of homelessness when applied to regional and rural mining communities. Further this paper explores the implications of the mining cycle, characterised by periods of economic boom and bust, on homelessness in communities which directly support the mining industry. The relative low profile given to homelessness in mining communities is situated within the dominant neo-liberalist paradigm which values immediate monetary and capital gain and individualism over and above structural responses to social and community issues.

\section{The significance of the recent 2003-2012 mining boom in Australia}

The mining and resources sector is central to debates about Australia's current and future economic and social prosperity (Edwards, 2014; Energy, 2007; MCA, 2011). Mining has long had a strong profile in many of Australia's regional and rural areas. The recent decade long mining boom in Australia is recognised as having begun in 2003 coinciding with a dramatic increase in the price of coal and other minerals such as iron ore on the world market. Coupled with a huge increase in the commodity price for these minerals was a commensurate huge increase in demand for these minerals from Australia from overseas and in particular China and India. This 10 year period became known as the mining boom. Regions including the North West Region of Queensland the Bowen Basin in Central Queensland rose to national and international attention as mining regions that were producing exceptional profits by mining companies which trickled down to well paid jobs in the mining sector which enabled an affluent lifestyle for many individuals and families employed through the mining industry. Discussion about opportunity was often framed about how individuals lucrative work in the mining sector which became part of the national psyche. Even during the Global Financial Crisis of 2008, the mining communities faired reasonably well and in some cases experienced further economic prosperity at a time when many other parts of Australia and the world were experiencing economic hardship. 
Debate first emerged in 2012 that in light of declining mining revenues and loss of mining industry jobs that the reality was the Mining Boom had actually ended (Fowler, 2012). While initial debate on this subject considered whether the 'downturn' was only a temporary adjustment to a different phase of mining activity, by 2014 the Australian Government acknowledged the end of the Mining Boom as a primary reason for decreased government revenue and justification for harsher Budget measures in 2014-15 (Hockey, 2014). The cyclical nature of mining booms has reignited the question of whether fiscal policy has been adequate during the boom times to ensure appropriate investment in Australia's future when boom periods inevitably end and to not any learnings from policy failures during these periods (Cleary, 2011). At a local level there are practical issues arising from this question about the health and wellbeing of rural and regional communities which support mining during these changes.

Many members of rural and regional communities see their future, indeed their survival as a community, as inextricably linked to future success of mining. Simply stated, if there is no future in mining there is no future for the community. Without the lure of well paying employment there is little to attract individuals and families to these communities. After a decade of considerable mining boom which transformed not only the lives of people engaged in mining employment but the very nature of mining communities, these communities are now faced with a series of complex questions about their medium and long term future. What are the full social impacts of mining boom? What relationship, if any, has the mining boom had on homelessness in mining communities? How do you prepare and plan at a community level for a future mining boom? What are the lessons to be learnt from the recent decade long mining boom? It is clear that mining communities in many instances have experienced and survived numerous periods of boom and bust throughout their history. Understanding the impact of this cycle on the community and in particular its more vulnerable citizens is a social planning and social and economic policy responsibility.

\section{Literature review of homelessness in Australian regional and rural mining communities}

Other than Australian Bureau of Statistics Census counts and the work of a few researchers, homelessness research in non-urban contexts is not well established in 
literature. It is however an emerging focus of scholars and policy writers (Maidment \& Bay, 2012). Homelessness research in rural communities and other countries shows a 'hidden homelessness' because people experiencing homelessness in these communities tend not to be visible rough sleepers as in large cities and these rural communities have fewer human services and resources available to support homeless people (Milbourne \& Cloke, 2006). Indeed the common perception of rural communities as being 'idyllic' places for families, even inclusive communities where everyone knows each other and offers support to one another has detracted from understandings of homelessness in these communities (Cloke, Milbourne, \& Widdowfield, 2002). These common perceptions of rural communities are often applied to mining communities throughout Australia. How could homelessness even exist in such an ideal and prosperous surroundings? Recent efforts by social researchers in Australia have begun the process of identifying and describing homelessness in Australia in a range of non-urban contexts and this paper continues this focus in considering the particular issues and dynamics that lead to homelessness in mining communities as well as the experience of homeless people in these communities. This paper critiques the existing homelessness knowledge base when applied to homelessness in mining communities.

This critique commences with an analysis of the major ways in which homelessness is defined and application of this definition to people experiencing homelessness in mining communities. The Australian Bureau of Statistics (ABS) released a statistical definition of homelessness to inform Census counting activities in 2012. According to the statistical definition of homelessness, a person may be deemed homeless if the person is living in a dwelling that is inadequate, or the person has no tenure over the property, or the initial tenure is short and not extendable and does not allow the person to have control of, and access to space for social relations (Australian Bureau of Statistics, 2012d). This definition replaced the earlier Cultural definition of homelessness as the approach taken to inform Census counts including the 2011 Australian Census (Chamberlain \& Mackenzie, 1992). The statistical definition of homelessness was formed as a response to some of the noted short comings of the cultural definition of homelessness and how Census activities were undertaken including the collection of Census data in regional and rural mining communities. One of the main limitations of definitions of homelessness is the exclusion of temporary workers living in makeshift accommodation or dongas 
through Fly In Fly Out (FIFO) or Drive in Drive Out (DIDO) arrangements. These workers who often spend more than 26 weeks of the years living as part mining communities or in neighbouring locations are still not counted as part of the Census data for the mining community as they are considered to have a permanent address somewhere else in Australia. There are also practical concerns raised about Census data undercounting the number of homeless people in rural communities because information is not available as to the person's current location and that there are too few Census staff able to check areas where homeless people may be residing. It is our view that these issues skew the quantitative data that Census counts provide in relation to homeless people in regional and rural mining communities.

Homelessness theory and knowledge is characterised by a number of key themes. These include access to housing; housing costs; pathways into homelessness and pathways out of homelessness and formal service system responses to homelessness (Chamberlain \& Mackenzie, 2006; Johnson, Gronda, \& Coutts, 2008). Collectively these inter-related bodies of knowledge contribute to our understanding of homelessness, its causes, consequences and societal responses. This body of work is urban-centric and has many limitations when used as the basis to understand homelessness in regional and rural mining communities.

While the exact relationship between people experiencing homelessness and access to housing options is debated, the underlying premise that lack of affordable housing options increases social marginalisation and homelessness within communities is widely accepted amongst academics and social policy analysts (Fitzpatrick \& Stephens, 2007; Rowley \& Ong, 2012; Stephens, Fitzpatrick, Elsinga, van Steen, \& Chzhen, 2010). This statement holds true across Australian cities and regions and in many overseas countries. Indeed inadequate affordable housing options for people has been a central issue for Australian mining communities during the mining boom where there was simply not enough social or private housing options available for community members. This was also the case for people interested in relocating to these communities to take up employment in what was then a lucrative mining industry. Census data shows a dramatic increase in population of mining communities from Census undertaken in 2001, 2006 and 2011.

Haslam-Mackenzie, Phillips, Rowley, Brereton and Birdsall-Jones (2009) identified the pressures that this swelling in population of mining communities had on Australian mining communities and how this trend decreased housing affordability 
and increased housing stress in these communities. This study also highlighted the trend of FIFO and DIDO workforce which tended to exacerbate these issues by virtue of increasing demand for housing. Additional pressures were created as a result of mining companies offering housing subsidies to staff which served to inflate housing prices in these communities. Community members and others seeking affordable housing were a clear loser during the height of the mining boom. Although there has been an improvement in housing affordability in mining communities since the end of the mining boom in 2012, access to affordable housing continues to be a major issue for these communities and one which needs to be recognised as a structural issue causing homelessness in these communities.

Explanations of homelessness based solely on housing supply and affordability arguments in regional and rural mining communities are limited and do not convey the complete picture of structural issues that cause homelessness in these communities. Chamberlain and Mackenzie (2006) developed a 'homeless careers' framework which considered the specific phases of experience leading to homelessness and these were considered in detail for people experiencing homelessness through family breakdown, housing crisis and youth homelessness. This career framework was developed further by Johnson, Gronda and Coutts (2008) who identified five specific 'pathways into homelessness', these being housing crisis, domestic violence, youth, mental health and substance abuse. This approach has been useful in understanding how different people come to experience homelessness in their lives. It follows that for each pathway into homelessness a different set of responses is required to assist people to obtain housing and support services which will end their experience of homelessness. While this approach is useful in understanding homelessness and helps to identify service delivery responses to different people experiencing homelessness, the approach does not seem to take into account the social issues, community factors and dynamics that are particular to mining communities. These social issues, community factors and dynamics include the culture of mining communities especially the dominant ethos of masculinity, the changing pattern of employment and working conditions for people employed by the mining industry and the impact on relationships and families, sense of social and geographic isolation, the rise in substance abuse, the prevalence of male on male violence and domestic violence, the huge demand for health and welfare services to the point that much of the need for these service goes unmet, to 
name only a few. Carrington and colleagues (Carrington, Hogg, \& Mclntosh, 2011) have described some of these social issues and dynamics as the 'underbelly of mining communities'. More work is required to unpack, critique and to develop the pathways approach to understanding homelessness in mining communities as well as people's pathways out of homelessness in these communities.

Aboriginal and Torres Strait Islander homelessness is also not well profiled in research on Australian mining communities. This is peculiar given so many mining communities have been established in regions with traditional land owners. Research on Aboriginal and Torres Strait Islander homelessness has increased over the last decade (Memmott, Long, Chamber, \& Spring, 2003; Parsell, 2011) however it has tended to avoid any explicit focus connect to regional and rural mining communities. The focus has tended to be on good service delivery responses to Aboriginal and Torres Strait Island people and the major issue of overcrowded housing in Aboriginal and Torres Strait Island communities (Memmott, Birdsall Jones, \& Greenop, 2012). It is widely recognised that Aboriginal and Torres Strait Islander people are over-represented in the homeless population throughout Queensland and Australia and it raises the question what, if any impact has the mining boom of the last decade and post boom era had on homeless Aboriginal and Torres Strait Islander people in these communities? It is important to establish the extent to which Aboriginal and Torres Strait Islander people in these communities have benefited, if at all, from the mining boom? How has the great wealth generation of this period served to help or hinder homeless Aboriginal and Torres Strait Islander people in mining communities? To understand the impacts of the recent mining boom on homelessness in these communities, the experiences of Aboriginal and Torres Strait Islander people over this corresponding period must also be understood.

\section{Is homelessness in mining communities a down payment on Australia's wealth} and prosperity during mining booms or an inevitable product of neo-liberalist society compounded during periods of mining down turn?

Mining booms and busts have long characterised Australia's economic and social history. They are anticipated to occur several times throughout one's life. The recent decade long mining boom is regarded as a long boom which generated huge wealth across sections of Australian society. But at what cost and what were the social 
consequences? During the years of the mining boom almost no media attention was directed at a possible 'downside' of the mining boom. The dominant perception of mining communities as places where short term wealth and material gain could be realised lead to an idealisation of mining communities. For many people the notion of people experiencing homelessness in mining communities during such prosperous times was unfathomable. This view slowly changed during the course of the mining boom but only really began to be recognised towards the very end of the boom cycle. The experience of the recent mining boom leaves us with the unanswered question as to whether homelessness is something we tacitly accept as a down payment on the incredible wealth and prosperity generated during boom times or inevitable product of a market driven, neo-liberalist society? A society which values an individualistic, short term culture of exploitation of mining wealth best exemplified by a take your money and run approach which serves to increase social marginalisation and exclusion for some community members who do not benefit from mining wealth and erode the social fabric of regional and rural mining communities over the medium to long term.

Homelessness has always been a feature of mining communities during boom and bust phases. Homelessness may not have been talked about in mining communities during much of the recent mining boom but it did affect the lives of many citizens. The Mackay region in central and north Queensland, encompassing the Bowen Basin, has been at the epicentre of debates of the impacts of mining at a national level. As a case study, the Bowen Basin has 41 operational mines (Queensland Government Statistician's Office, 2014) which produce the largest amount of coal in Queensland, as well as other minerals, and contributes significantly to the Queensland and Australian economies. In the last three years of the mining downturn there has been an increased focus on the social impacts of on these communities. The social disadvantage indicators at the peak of the mining boom, namely the level of unaffordable housing, relative access to health and other vital community services, high demand on community infrastructure and evidence of family breakdown, domestic violence and substance abuse now also include indicators such as high levels of unemployment, people who have been caught with high levels of debt and ongoing housing affordability issues for people on low incomes. All of these issues need to be understood in terms of their contribution to the structural causes of homelessness in mining communities. This then leads to the 
question what do we know about the level of homelessness in mining communities during boom and bust mining cycles?

The Australian Bureau of Statistics Census counts which occur every five years continue to be the only reliable method of estimating homelessness throughout Australia. As a relevant case study, the Mining Region of Mackay and the Bowen Basin are a relevant geographic mining area to ascertain quantifiable increases in homelessness from Census data over the last 15 years. Table 1 below shows the increase in homeless people in the major communities of Mackay, Belyando and Broadsound within the Bowen Basin from ABS Census counts in 2001, 2006 and 2011.

Table 1

Homeless People in Mackay, Broadsound, Belyando and the Bowen Basin

\begin{tabular}{lllll}
\hline $\begin{array}{l}\text { Community/ } \\
\text { Geographic }\end{array}$ & $\begin{array}{l}\text { Number } \\
\text { Homeless People }\end{array}$ & Homeless & People & of \\
Catchment & -2001 Census & -2006 Census & -2011 Census \\
\hline Mackay & 201 & 400 & 583 \\
\hline Belyando & 110 & 255 & -
\end{tabular}

\begin{tabular}{ll|} 
Broadsound & 39
\end{tabular}

Bowen Basin

202

Moranbah

74

Broadsound

25

Nebo

Note - data for the Bowen Basin was only made available for the 2011 Census. Prior to this, a different geographical classification system had been used which included a large portion of the Bowen Basin counted in the Belyando statistical area. This revised system makes it difficult to indicate homelessness in the Bowen Basin 
over a time line series. The Bowen Basin includes a number of communities including Bowen, Moranbah, Broadsound-Nebo, Clermont and Collinsville.

Source: (Australian Bureau of Statistics, 2012a, 2012b; Statistics, 2012c)

The ABS Census data shows an increasing pattern of homelessness in Mackay from 2001 to 2011. In fact homelessness doubled between 2001 and 2006 and increased by almost 150\% between 2006 and 2011. Assessing the homelessness population data in the Bowen Basin Region is somewhat more complicated due to changes in geographical classification systems used to record Census data for this area. We can see large increase in homeless people between 2001 and 2006 in the former Belyando area which includes the mining communities of Moranbah and Clermont. On the other hand we see a slightly reduced level of homelessness between 2001 and 2006 in the Broadsound statistical area which includes the communities of Dysart and Nebo. Homelessness in Broadsound-Nebo area appears to have remained somewhat consistent from 2006 to 2011 . The 2006 and 2011 Census data was captured at a time when the mining boom was at its height in this region. The 2016 Census will provide useful information to assess homelessness in these communities at a time when mining has experienced a considerable period of downturn.

Mining communities in this region experienced overall population growth from 2001 to 2011, in some instances rapid population growth within a two year period, this on its own cannot be used to justify the large increases in numbers of homeless people who were identified in Mackay and the Bowen Basin during the 2011 Census. We also know that for a variety of reasons, this data is more than likely to have been a conservative estimate of homeless people on Census night given what we acknowledge are the inherent difficulties locating homeless people during census counting periods and potential undercounting of people in rural and remote areas and Aboriginal and Torres Strait Islander people (Chamberlain \& Mackenzie, 2009). The methodological issues associated with Census homelessness data and the reliability of this data for mining communities has been a long standing concern hence why the ABS are at pains to point out the data is only an estimate. If we are to improve service delivery to homeless people in mining communities, indeed any nonmetropolitan area, we do need to appreciate the factors which cause homelessness 
in these communities as well as the factors which help to reduce homelessness and promote social participation and community development.

\section{Implications for research, social policy and planning}

Given the uncertainty facing mining communities there is an urgent need to assess the impact the mining industry and the decade long boom has had on homelessness in regional Australian communities. There is also a need to consider the impact of the current mining downturn on homelessness in mining communities. There is little doubt that homelessness has become a feature of mining communities in quite unique ways. The specific characteristics of homelessness in mining communities need to be recognised to contrast homelessness in mining communities with homelessness in other Australian communities and regions to design appropriate housing, support and broader social policy responses. Further dialogue between all levels of Government and Industry will be critical to clarify roles in relation to addressing the challenges of homelessness in mining communities.

The urgency has arisen as a result of the systemic neglect of properly planning for social policy in mining communities. A common perception is that the mining boom has more positively impacted business and companies and citizens residing in the large metropolitan cities of Australia in contrast to smaller regional and rural communities who directly support the mining industry. The benefits of the boom have been viewed as disproportionately advantaging cities at the expense of regional and rural mining communities that have provided housing for workers and their families and vital services such as roads, hospitals and schools. This was dramatically captured in the title of the Australian Government Standing Committee on Regional Australia's Report (Commonwealth of Australia, 2013) Cancer of the Bush or Salvation of our Cities examining the impacts of FIFO and DIDO workforce arrangements on regional communities. With the use of such remarkable language which pits communities against each other, it is easy to form the impression that the future of regional and rural mining communities is at odds with other regions in Australia. In fact there is some evidence from recent elections throughout Australia, that this division has resonated with the voting public who have to some extent shifted their support to political parties which explicitly champion the return of profits to regions and promote regional communities as being attractive for young families. The National Party in Western Australia achieved political success with the 
implementation since 2008 of its Royalties for Regions policy which has guaranteed $25 \%$ of Western Australia's mining and petroleum royalties to be retained for regional infrastructure investment (Brown \& Bellamy, 2010). In a similar vein, the Katter Australian Party has also achieved a degree of political success in Queensland through championing a return of mining profits to regions. The Katter Australian Party won the regional seats of Mt Isa and Dalrymple covering mining areas of in the North West Queensland the Bowen Basin in the 2012 Queensland State Election and retained these two seats at the 2015 Queensland State Election. The need for an inclusive macro-political approach to addressing the challenges facing mining communities would seem obvious but remains elusive. In the post mining boom era this approach to politics will define many of the looming public policy debates including affordable housing, cost of living pressures and community infrastructure.

Housing has to suit the needs of the community and reflect the diversity of community membership. The provision of appropriate and affordable housing is central to individual health and wellbeing in mining communities. Housing is recognised as a vital component of the physical infrastructure supporting the mining industry (Haslam Mackenzie et al., 2009) but is often not addressed in community planning or housing supply activities. In the current period of mining downturn some mining communities are experiencing a rise in vacant and affordable houses. Hence the significant housing construction and supply work down which was undertaken at the height of the mining boom only three years ago would seem to be too little too late. What is more the investors in this housing construction are faced with huge debts and reduced likelihood of repaying debts commensurate with previous expectations of owners or investors accessing lucrative mining income. The affordability of housing in mining communities takes on added significance for community members on low incomes who may not be employed either directly or indirectly through the mining industry. These people include staff in supermarkets, fast food services, retail assistants, small business and others who were previously excluded from the housing market during the boom. It is possible that this group of people are now able to access more affordable housing in mining communities but it is also likely these people are faced with unemployment or significant loss of business due to the mining downturn. Many of these people have simply been forced to leave the community to locate employment in other regions. 
In the context of declining government revenues and resources available for human services, corporate social responsibility in mining communities becomes a crucial social policy issue. Over the last decade many mining companies have worked in partnership with local communities and with different levels of government to deliver important infrastructure and services. Importantly this commitment to building infrastructure and service delivery has included examples of where contributions have been made to important human services including services for homeless people. The role of mining companies as stakeholders who actively participate in dialogue and planning to improve social and community outcomes for communities that provide such vital support to their industry is widely accepted as a legitimate task for mining companies (Schwarz, 2007; Warburton, Shapiro, Buckley, \& van Gellecum, 2004). Further efforts are needed to engender greater cohesion and clarity of purpose for all stakeholders, government, non-government organisations, housing providers, mining companies and others interested in achieving improved community outcomes. It would also be logical that further dialogue occurs between stakeholders about how corporate social responsibility can further contribute towards the goals of reducing homelessness in mining communities.

Finally, further social research focusing on homelessness issues in mining communities is urgently needed. The research to date, while particularly sparse and circumspect, highlights the potential for new knowledge and insight about causes of homelessness. It also shows that existing homelessness knowledge base of theories and concepts - largely developed from urban settings - are not always easily applied to the people experiencing homelessness in mining communities because of the particular community dynamics associated with the boom and downturn mining cycle. This research would serve strengthen responses to homelessness in the future during other phases of the mining boom and downturn cycle.

\section{Conclusion}

Homelessness in Australian mining communities is not well understood. The evidence base is weak and policy addressing homelessness in these communities is under-developed. Moreover, much of the traditional, orthodox understanding of homelessness, which has emerged from large urban communities, appears 
inadequate when applied to the experiences of homeless people in mining communities. Homelessness in mining communities was not a topic of public interest during the years of the mining boom and this lack of recognition does support the argument that during the mining boom years, homelessness was widely viewed as an unfortunate but necessary down payment for the huge mining wealth which was generated and perceived to be in the greater interests of Australian economy and society. The downturn in mining over the last three years has seen has seen a shift in Australia's fortunes. This shift makes us reconsider our view of homelessness and ultimately how we decide to respond to the challenges of homelessness throughout Australia particularly in mining regions and other non-metropolitan areas. Homelessness in mining communities needs to be seen in the context of the neoliberalist paradigm which characterises Australia's social policy settings and welfare system. The extent to which homelessness will be allowed to be constructed as an inevitable product of this hostile environment to collectivist social welfare approaches and long term community planning will be a major point of contention during social and political debates taking place in the current period of mining downturn. This will in turn inform preparedness to address homelessness in mining communities in the future irrespective of the incredible highs and lows associated with the mining boom and downturn cycle.

\section{References}

Australia, H. o. R. S. C. o. R. (2013). Cancer of the bush or salvation for our cities? fly-in, fly-out, drive-in, drive-out workforce practice in regional Australia. Canberra: Commonwealth of Australia.

Brown, A. J., \& Bellamy, J. (2010). In the shadow of federalism: Dilemmas of institutional design in Australian rural and remote regional governance. Australasian Journal of Regional Studies, 16(2), 151-181.

Carrington, K., Hogg, R., \& Mclntosh, A. (2011). The resource boom's underbelly: Criminological impacts of mining development. Australian and New Zealand Journal of Criminology, 44(3), 335-354.

Chamberlain, C., \& Mackenzie, D. (1992). Understanding contemporary homelessness: Issues of definition and meaning. Australian Journal of Social Issues, 27(4), 274-297.

Chamberlain, C., \& Mackenzie, D. (2006). Homeless careers: A framework for intervention. Australian Social Work, 59(2), 198-212.

Chamberlain, C., \& Mackenzie, D. (2009). Counting the homeless: Queensland (Vol. Cat. No. HOU 205.). Canberra.

Cleary, P. (2011). Too much luck: The mining boom and Australia's future. Sydney: Black Inc. 
Cloke, P., Milbourne, P., \& Widdowfield, R. (2002). Rural homelessness: Issues, experiences and policy responses. Bristol: The Policy Press.

Edwards, J. (2014). Beyond the boom. Melbourne: Penguin Books.

Energy, Q. G. D. o. M. a. (2007). Queensland mining industries: A report on the economic significance of mining and mineral processing to the Central Region. Brisbane.

Fitzpatrick, S., \& Stephens, M. (2007). An international review of homelessness and social housing policy. Yorkshire, United Kingdom.

Fowler, A. (Writer). (2012). Four Corners (ABC) [Television]. In A. Fowler \& P. Cronau (Producer), Casualities of the boom.

Haslam Mackenzie, F., Phillips, R., Rowley, S., Brereton, D., \& Birdsall-Jones, C. (2009). Housing market dynamics in resource boom towns (Final Report No. 135). Australia.

Hockey, T. H. J. B. (2014). Budget speech 2014-15. Retrieved from www.budget.gov.au/2014-15/content/speech/html.

Johnson, G., Gronda, H., \& Coutts, S. (2008). On the outside: Pathways in and out of homelessness. Melbourne: Australian Scholary Publishing.

Maidment, J., \& Bay, U. (Eds.). (2012). Social work in rural Australia. Sydney: Allen \& Unwin.

MCA. (2011). Minerals Council of Australia annual report 2011. Australia.

Memmott, P., Birdsall - Jones, C., \& Greenop, K. (2012). Australian Indigenous house crowding AHURI (Final Report No. 194). AHURI Queensland Research Centre: Australian Housing and Urban Research Institute.

Memmott, P., Long, S., Chamber, C., \& Spring, F. (2003). Categories of Indigenous homeless people and good practice responses to their needs AHURI (Final Report No. 49). AHURI Queensland Research Centre: Australian Housing and Urban Research Institute.

Milbourne, P., \& Cloke, P. (Eds.). (2006). International perspectives on rural homelessness. London: Routledge.

Office, Q. G. S. (2014). Bowen Basin population report June 2014. Brisbane: Queensland Treasury and Trade. Retrieved from www.qgso.qld.go.au/products/reports/bowen-basin-pop-report/bowen-basinpop-report-2014

Parsell, C. (2011). Responding to people sleeping rough: Dilemmas and opportunities for social work. Australian Social Work, 64(3), 330-345.

Rowley, S., \& Ong, R. (2012). Housing affordability, housing stress and household wellbeing in Australia AHURI (Final Report; no. 192 Vol. No. 192). Melbourne: Australian Housing and Urban Research Institute.

Schwarz, M. (2007). Corporate responsibility and Australian business: Identifying the issue. Australian Journal of Social Issues, 42(3), 419-426.

Statistics, A. B. o. (2012a). 2049 Census of population and housing - estimating homelessness 2001. Retrieved from www.abs.gov.au

Statistics, A. B. o. (2012b). 2049 Census of population and housing - estimating homelessness 2006. Retrieved from www.abs.gov.au

Statistics, A. B. o. (2012c). 2049 Census of population and housing - estimating homelessness 2011. Retrieved from www.abs.gov.au

Statistics, A. B. o. (2012d). Information paper - a statistical definition of homelessness. Canberra.

Stephens, M., Fitzpatrick, S., Elsinga, M., van Steen, G., \& Chzhen, Y. (2010). Study on housing exclusion: Welfare policies, housing provision and labour markets. 
Warburton, J., Shapiro, M., Buckley, A., \& van Gellecum, Y. (2004). A nice thing to do but is it critical for business? Corporate responsibility and Australian business. Australian Journal of Social Issues, 39(2), 117-127.

\section{Biographical notes}

Mr Shane Warren is a PhD Student with the School of Human Services and Social Work. Mr Warren's doctoral study focuses on homelessness in Central Queensland mining communities and how the mining boom and downturn has impacted housing and homelessness issues in these communities. Mr Warren has over 20 years of experience as a qualified social worker which has included significant amounts of time spent working in the delivery of human services in Central Queensland communities.

Dr Donna McDonald is Senior Research Fellow and Convenor of Disability Studies in the School of Human Services and Social Work at Griffith University. She is currently leading an NDIS Readiness Research Partnership with Endeavour Foundation which aims to get an improved understanding of Endeavour Foundation clients' lived experiences of disability service delivery before and after the NDIS. Donna has extensive policy networks, developed throughout her 30-year career in public policy as a social worker, policy adviser and writer working at federal, state and local government levels in Australia and England. Donna's book, The Art of Being Deaf: a memoir, was published by Gallaudet University Press, Washington, in March 2014.

Associate Professor Donna McAuliffe is Deputy Head of School (Learning \& Teaching) in the School of Human Services and Social Work, Griffith University. She has an extensive research, teaching and publication history in the area of ethics and professional practice, with a focus on inter-professional ethics. Donna supervises a number of higher degree research candidates with interests in diverse areas in the social, health and human services. She has particular experience with research projects that focus on contemporary issues in rural and remote practice. 